\title{
Perfil do profissional contábil: estudo comparativo entre as exigências do mercado de trabalho e a formação oferecida pelas instituições de ensino superior de Curitiba
}

Accounting professional profile: a comparative study between the demands of the labor market and knowledge offered by institutions of higher education in Curitiba

\author{
Daniel Ferreira dos Santos \\ Graduando em Administração pela Universidade Positivo \\ Endereço: Rua Prof. Pedro Viriato Parigot de Souza, 5300 - Campo Comprido \\ CEP : 81280-330 - Curitiba/PR - Brasil \\ E-mail: danielsantos927@hotmail.com \\ Telefone: (41) 9947-4282
}

\section{Fernanda de Souza Sobral}

Graduada em Administração pela Universidade Positivo

Endereço: Rua Prof. Pedro Viriato Parigot de Souza, 5300 - Campo Comprido

CEP : 81280-330 - Curitiba/PR - Brasil

E-mail: fernanda.sobral@maflow.com.br

\section{Michael Dias Correa}

Mestre em Contabilidade pela Universidade Federal do Paraná

Professor da Universidade Positivo

Endereço: Rua Prof. Pedro Viriato Parigot de Souza, 5300 - Campo Comprido

Curitiba - PR - CEP - 81280-330

E-mail:micdias@hotmail.com

Telefone: (41) 3317-3000

\section{Tatiane Antonovz}

Mestre em Contabilidade na Universidade Federal do Paraná

Professora no curso de Ciências Contábeis na Faculdade Estácio de Curitiba.

Endereço: Rua Governador Agamenon Magalhães, n॰ 173, Apto 702 B, Bairro Cristo Rei

CEP: 80050-510 - Curitiba/PR - Brasil

E-mail: tatiane152@hotmail.com

Telefone: (41) 3308-7957

\section{Ronaldo Ferreira dos Santos}

Graduando em Administração pela Universidade Positivo

Endereço: Rua Prof. Pedro Viriato Parigot de Souza, 5300 - Campo Comprido

CEP : 81280-330 - Curitiba/PR - Brasil

E-mail: ronaldosnts@hotmail.com

(41) 9940-9249 


\title{
Resumo
}

O objetivo geral do estudo é verificar se a formação acadêmica em Ciências Contábeis oferecida pelas Instituições de Ensino Superior (IES) condiz com as necessidades do mercado de trabalho na área contábil. Trata-se de uma pesquisa descritiva, os dados foram coletados nos anúncios de emprego para os profissionais da área contábil, e nas grades curriculares do curso de Ciências Contábeis das IES de Curitiba. Observou-se que a maioria das vagas são destinadas a profissionais de nível auxiliar; a maioria das vagas exige experiência profissional; os conhecimentos relacionados à contabilidade e a Legislação societária e tributária são os mais requeridos para os níveis de auxiliar e chefia, enquanto que para o nível de gerencia os mais exigidos foram os conhecimentos em administração, Economia e Finanças. Verificou-se também que as IES estão alinhando suas matrizes curriculares de maneira a oferecer a melhor colocação no mercado de trabalho aos seus formandos.

Palavras-chave: Profissional contábil. Perfil profissiográfico. Instituições de ensino superior.

\begin{abstract}
The overall objective of the study is to verify that the academic background in Accounting offered by Higher Education Institutions (HEI) is consistent with the needs of the job market in accounting. It is a descriptive study, data were collected in job advertisements for professionals in the accounting area, and in the course curricula of Accounting HEIs in Curitiba. It was observed that a majority of seats are designed to help professional level, most jobs require experience, knowledge related to accounting and corporate and tax law are the most required for help and leadership levels, while for level of management were the most demanded in the knowledge administration, economics and finance. It was also found that HEIs are aligning their curricular so as to offer the best placement in the labor market to their students.
\end{abstract}

Keywords: Professional accounting. Professional profile. Institutions of higher education.

\section{Introdução}

O profissional contábil exerce um papel de grande responsabilidade para a sociedade. A função por ele assumida, suas prerrogativas profissionais e o conjunto de informações por ele gerenciadas, o tornam um dos principais agentes no processo de gestão das entidades. Contudo, para poder responder às necessidades que o cercam é fundamental que ele entenda, claramente, qual a sua relevância e atividade na sociedade.

Segundo Mohamed e Lashine (2003, apud PIRES et al. 2009) a atuação do contador tem sofrido alterações nos últimos anos, devido a fatores como a globalização e as inovações tecnológicas da informação, essas modificações exigem do contador o desenvolvimento de novas competências, habilidades e conhecimentos nas áreas relacionadas à comunicação, informática, conhecimentos globais, análise, entre outras.

Leal et al (2008) afirmam que o perfil profissional do contador precisa ser remodelado, para que assim possa atender as exigências das organizações.

O mercado exige dos profissionais da área contábil um conhecimento que transcende o processo específico pronto para o tecnicismo; busca- 
se um profissional com competências para entender o "negócio", visando orientar o gestor e participar das decisões de forma consciente. Dessa forma, recai para os profissionais a exigência de um novo perfil, mais condizente com a atual dinâmica assumida pelas organizações. (LEAL et al., 2008, p.2).

Sobre essas mudanças Faria e Queiroz (2009), enfatizam que a formação acadêmica é fundamental, pois permite que os futuros e atuais contadores estejam preparados e atentos para enfrentar os desafios a eles apresentados.

Sendo assim, a questão de pesquisa desse trabalho é: As IES estão formando profissionais com as competências exigidas pelo mercado de trabalho?

O objetivo principal desse trabalho é traçar o perfil do contador demandado pelo mercado de trabalho de Curitiba - Paraná, a fim de verificar se o processo educacional atualmente desenvolvido contribui ou não para a ampliação das oportunidades e valorização profissional dos acadêmicos formados em Ciências Contábeis.

O presente estudo limita-se a um número relativamente pequeno de IES, comparado ao número total de IES que possuem o curso de Ciências Contábeis em Curitiba. Também, a análise de mercado poderá não englobar todas as empresas e vagas de emprego disponíveis para Curitiba. É importante ressaltar ainda que a definição do perfil profissiográfico do profissional contábil proposto por esse trabalho não poderá englobar atividades importantes como: empresários do ramo contábil, peritos, professores/pesquisadores, profissionais que atuam na área pública. Essa limitação deve-se ao fato de que a pesquisa foi realizada no âmbito das funções e cargos que são objeto de contratação pelas empresas dos mais diversos segmentos de atuação.

Além da introdução, o presente artigo é dividido em mais 5 (cinco partes). No referencial teórico são abordadas as questões relacionadas ao mercado de trabalho, ao histórico da profissão contábil, assim como o ensino. Na terceira parte da pesquisa são definidas as características metodológicas da mesma. $\mathrm{Na}$ quarta parte são apresentados e analisados os dados e por fim na quinta parte são apresentadas as conclusões do artigo seguidas das referências bibliográficas.

\section{Fundamentação Teórica}

Nesta seção será demonstrado o referencial teórico no qual se apoia o presente estudo, inicia-se pela evolução da profissão contábil, seguido do mercado de trabalho do contador contemporâneo e por fim será apresentado o perfil das instituições de ensino superior na formação dos profissionais contábeis. 


\subsection{A Evolução da Profissão Contábil}

A evolução da contabilidade está diretamente associada à evolução da sociedade, pois, conforme Iudícibus "em termos de compreensão da evolução contábil histórica raramente o 'estado da arte' ultrapassa o grau de evolução econômica, institucional e social das sociedades analisadas, em cada época.” (2006, p.35 apud PELEIAS et al. 2007)

No Brasil não foi diferente, pode-se dizer que a profissão era exercida no país desde o inicio da colonização, já que em 1549 ocorreu a primeira nomeação feita por Dom João III para contador geral e guarda-livros (COELHO, 2000). Porém, o primeiro relato contábil é datado de 1770, quando o Rei de Portugal expediu uma carta determinando que todos os guarda-livros deveriam se matricular na Junta do Comércio, sendo assim essa data pode ser considerada como a primeira regulamentação da profissão no Brasil.

A profissão contábil passou a se desenvolver com mais força no país, devido à expansão do comércio com a chegada da corte portuguesa em 1807 e com a instalação do governo provisório de Dom João VI, em 1808. A Lei $n^{\circ}$ 556 de 25 de julho de 1850 instituiu o Código Comercial, tornando obrigatória a escrituração contábil e a elaboração anual das demonstrações do Balanço geral. Segundo Schimidt (2000) essa foi um grande avanço, se tratando de legislação, para o desenvolvimento da contabilidade. $O$ autor ainda ressalta que por não adotar um padrão a norma permitiu aos contadores brasileiros utilizar as mais variadas tendências doutrinárias para execução de suas atividades.

Em 22 de agosto de 1860, a Lei Imperial 1.083, conhecida como a Lei dos entraves, é considerada a primeira Lei das Sociedades por Ações. Regulamentada em 03 de novembro do mesmo ano pelo Decreto 2.679, objetivava corrigir alguns pontos do código comercial, determinando a obrigatoriedade da publicação e entrega ao Governo das demonstrações, conforme modelos e prazos por ela estabelecidos. (IUDÍCIBUS; RICARDINO FILHO, 2002 apud GUIMARÃES, 2006). Em 1902 surge a Academia de Comércio do Rio de Janeiro e a Escola Prática de Comércio de São Paulo, sob influência da Escola Italiana, foram uma das primeiras a organizar o curso destino a formação dos Guarda-livros (LAFFIN, 2005).

Em 1931, através do Decreto 20.158 a profissão do contador foi regulamentada e o ensino de contabilidade organizado. A segunda Lei das Sociedades por Ações foi instituída em 1940 pelo Decreto-Lei 2.627. A nova lei estabeleceu procedimentos para a contabilidade nacional, como regras para avaliação de ativos, e para apuração e distribuição de lucros, criação de reservas, e padrões para a publicação do balanço e da demonstração de lucros e perdas.

No ano de 1946 com o Decreto-Lei n ${ }^{\circ} .9 .295$ surgem o Conselho Federal e os Conselhos Regionais de Contabilidade, responsáveis por fiscalizar e organizar a classe contábil. O decreto também definiu o efetivo perfil dos profissionais de 
contabilidade e limitou as atribuições dos contabilistas.

A Lei $n^{0}$ 3384/58 dá nova denominação a profissão de guarda-livros, determinando que os profissionais habilitados como guarda-livros e técnicos em contabilidade deveriam integrar a categoria profissional dos técnicos em contabilidade, com as atribuições e prerrogativas até então dos guarda-livros. No mesmo ano o Conselho Federal de Contabilidade (CFC) por meio da resolução declara atividade privativa dos contabilistas a escrituração dos livros fiscais.

Outro acontecimento importante para a área contábil segundo Laffin (2005), na década de 1970, foi a Lei 6.404/76, chamada de Lei das Sociedades Anônimas, que alterou de forma significativa a estrutura contábil, até então existente.

Já na década de 2.000, a Comissão de Valores Mobiliários - CVM elaborou um Anteprojeto de Lei para reforma da Lei das Sociedades por Ações (Lei 6.404/76) com a finalidade de modernizar e harmonizar a lei societária em vigor com melhores práticas contábeis internacionais, visando à inserção do Brasil no atual contexto de globalização econômica.

Em 28 de dezembro de 2007 foi promulgada a Lei 11.638/07, que altera, revoga e introduz novos dispositivos à Lei das Sociedades por Ações (Lei ${ }^{\circ}$ 6.404/76). Segundo Santos e Calixto (2010) esta lei determinou a harmonização contábil com o IFRS (International Financial Reporting Standard), alinhando o Brasil ao processo de internacionalização da contabilidade. No ano de 2010 , foi publicada a Lei 12.249 que, entre outras providências, altera o Decreto-Lei $\mathrm{n}^{\circ}$ 9.295/46, que regulamenta a profissão contábil no território nacional.

\subsection{O Mercado de Trabalho do Contador Contemporâneo}

A contabilidade passou modificações ao longo dos anos, sempre objetivando oferecer informações com mais qualidade e adequadas às exigências do mercado. Neste sentido depois de analisado o histórico da profissão contábil é possível perceber que houve mudanças no mercado de trabalho do profissional de contabilidade.

Conforme Pires et al. (2009, p.159) alguns autores têm a percepção que "a tendência de que o mercado de trabalho, neste novo ambiente de negócios, demande um profissional capaz de auxiliar na gestão das organizações, não apenas processando informações que serão utilizadas pelos gestores, mas também as analisando e participando do processo decisório".

Em contrapartida pesquisas realizadas por outros autores "evidenciam uma predominância de atividades ligadas à contabilidade financeira e fiscal, o que sugere que os conhecimentos, habilidades e atitudes relacionadas ao desempenho de atividades voltadas ao atendimento das exigências legais ainda são as mais 
requeridas pelas organizações" (PIRES et al., 2009, p.159).

Machado e Nova (2008) traçaram um comparativo entre as exigências do mercado na cidade de São Paulo e as expectativas dos alunos, formandos em Ciências Contábeis, sobre a profissão. A pesquisa revelou que as empresas valorizam o perfil do contador voltado para o usuário final da contabilidade, com conhecimentos específicos em práticas contábeis, raciocínio matemático e informações aos usuários. Porém os alunos pesquisados mostraram um perfil do profissional contábil mais voltado à gerência. Esse conflito de perfis faz com que os alunos não se sintam aptos a atuar em um mercado tão exigente quanto aos conhecimentos específicos.

Outra pesquisa realizada por Leal et al. (2008) na cidade de Uberlândia classificou as exigências do mercado para o profissional em conhecimentos específicos, capacidades/ habilidades e atitudes, também as comparando com as perspectivas dos alunos formandos em Ciências Contábeis.

Assim como na pesquisa de Machado e Nova (2008), Leal et al (2008) percebeu que as exigências do mercado não estavam totalmente alinhadas com a perspectiva que os alunos tinham do mercado. Para os autores "isso indica que as IES devem estar atentas às necessidades do mercado, adequando seus métodos de ensino e currículos" (LEAL et al., 2008, p.158).

Também há estudos que aprofundaram em áreas específicas de atuação do contador conforme a pesquisa de Santana Júnior et al (2008) que buscou identificar o perfil do profissional contábil que atua na área pública, através da análise das provas aplicadas nos concursos. Os autores concluíram que as exigências contidas nas provas buscam um profissional tecnicista, sem levar em consideração a capacidade intelectual de criação e de crítica.

Já Queiroz e Faria (2009) tiveram como objeto de sua pesquisa os conhecimentos necessários ao profissional que atua com contabilidade internacional. Foi identificado pelos autores que do total de vagas coletadas em São Paulo em $20078,8 \%$ destinavam-se aos profissionais que atuam nessa área contra 4,6\% para o ano de 2008 .

\subsection{Perfil das IES na Formação dos Profissionais}

Sobre o papel das IES Ott e Pires (2010) afirmam que:

Estas devem atender às suas necessidades através do "produto" que colocam no mercado - o bacharel em Ciências Contábeis, viabilizando por meio dos currículos dos cursos o desenvolvimento e o aprimoramento das habilidades e dos conhecimentos requeridos para que ele possa desempenhar suas atividades de maneira adequada (PIRES; OTT, 2010, p.29). 
Os autores acreditam que as IES que possuem a preocupação de formar profissionais aptos à inserção no mercado de trabalho, devem oferecer uma formação capaz de suprir a demanda por profissionais qualificados. Pires e Ott (2010) ainda destacam que esse tipo de atitude trás benefícios para as três esferas envolvidas: as IES, os profissionais e para os empregadores.

As IES são beneficiadas ao oferecer ensino alinhado às exigências do mercado, dado que lhes confere um diferencial competitivo. Por sua vez, os profissionais recebem formação de alto nível, conseguindo se inserir no mercado de trabalho, que sai ganhando por poder dispor de profissionais qualificados para agregar conhecimento as suas organizações.

No Brasil, o Conselho Nacional de Educação estabelece as diretrizes curriculares para o curso de Ciências Contábeis. A resolução CNE/CSE 10/2004 trata do perfil desejado do profissional, as competências, habilidades e conteúdos curriculares.

Essa preocupação também é observada entre os órgãos internacionais, como é o caso da Organização das Nações Unidas (ONU), que em 1999, criou um currículo global para o Curso de Ciências Contábil. Essa proposta de formação do Contador Global já sofreu atualização no ano de 2003.

\section{Metodologia}

\subsection{Características da Pesquisa}

Quanto ao objetivo o tipo de pesquisa adotada foi a descritiva, onde segundo Andrade (2002, apud BEUREN et al., 2003, p.81) a pesquisa descritiva preocupa-se em observar os fatos, registrá-los, analisá-los, classificá-los e interpretá-los, e o pesquisador não interfere neles.

O procedimento de pesquisa é o documental, utilizando documentos de primeira mão, ou seja, os sites com oportunidades de emprego para profissionais contábeis, além das informações sobre a oferta do curso de Ciências Contábeis existentes no site das IES. A abordagem do problema se dará de forma qualitativa, que segundo Beuren et al. (2003, p.92) concebem análises mais profundas em relação ao fenômeno que está sendo estudado, tornando assim, possível relacionar o perfil dos profissionais demandados pelo mercado e o perfil de profissional formado pelas IES.

\subsection{População e Amostragem}

Segundo Beuren et al. (2003) população é a totalidade de elementos distintos que possuem certas características em comum definidas para determinado 
estudo. Pode-se definir como população da pesquisa: o mercado de trabalho para o profissional contábil na cidade de Curitiba e as IES que ofertam graduação em Ciências Contábeis.

A amostragem utilizada foi por acessibilidade. Neste caso, a pesquisa será restrita à Universidade Positivo (UP), Universidade Tuiuti do Paraná(UTP), Pontifícia Universidade Católica do Paraná (PUCPR) e o Centro Universitário Franciscano do Paraná (FAE). Em relação às vagas utilizadas para análise, as mesmas serão coletadas do site de recrutamento da empresa Catho Online, escolhida por apresentar-se como uma das empresas de maior credibilidade no mercado e que possui maior número de vagas e informações sobre estas.

\subsection{Coleta de Dados}

A coleta de dados do presente trabalho ocorreu entre os meses de junho a agosto de 2010, onde foram pesquisadas todas as vagas de emprego divulgadas, dentro das limitações da amostra determinada.

$\mathrm{Na}$ coleta, foram consideradas apenas as vagas oferecidas por empresas que exigiam como requisito, profissionais que concluíram ou que cursam a graduação em Ciências Contábeis. Assim, ficando fora da coleta as ofertas de emprego para os Técnicos em Contabilidade e as vagas destinadas a profissionais autônomos, empresários de contabilidade, professores universitários e funcionários públicos.

A coleta de dados foi feita com base no modelo utilizado por Guimarães (2006), onde o instrumento classifica as ofertas quanto: à fonte; ao tipo de cargo ofertado (se exclusivo para contadores ou não); ao nível hierárquico da vaga (auxiliar, chefia ou gerência); à descrição do cargo; às características gerais da empresa (nome, ramo de atividade, porte e origem); aos conhecimentos, habilidades e atitudes solicitados pelo empregador; e ao tempo mínimo de experiência profissional requerida.

\section{Análise dos Resultados}

\subsection{Perfil do Profissional Contábil}

A análise a seguir refere-se à determinação do perfil do profissional de contabilidade através dos resultados da pesquisa realizada com a coleta de vagas direcionadas a esse profissional na cidade de Curitiba.

Os dados foram tabulados na planilha eletrônica Excel ${ }^{\circledR}$ devido as facilidade no manuseio dos dados proporcionados por esse aplicativo do Microsoft

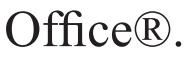




\subsubsection{Ofertas por Nível Hierárquico}

A amostra é composta por 254 anúncios de vagas, sendo que desse total $76,77 \%$ é destinada ao nível auxiliar, $15,35 \%$ ao nível de chefia e $7,87 \%$ a cargos de nível gerencial, conforme o gráfico 1 . Neste gráfico, é possível perceber que a maioria das vagas são destinadas a profissionais de nível auxiliar.

Gráfico 1 - Representatividade dos níveis hierárquicos no total de vagas

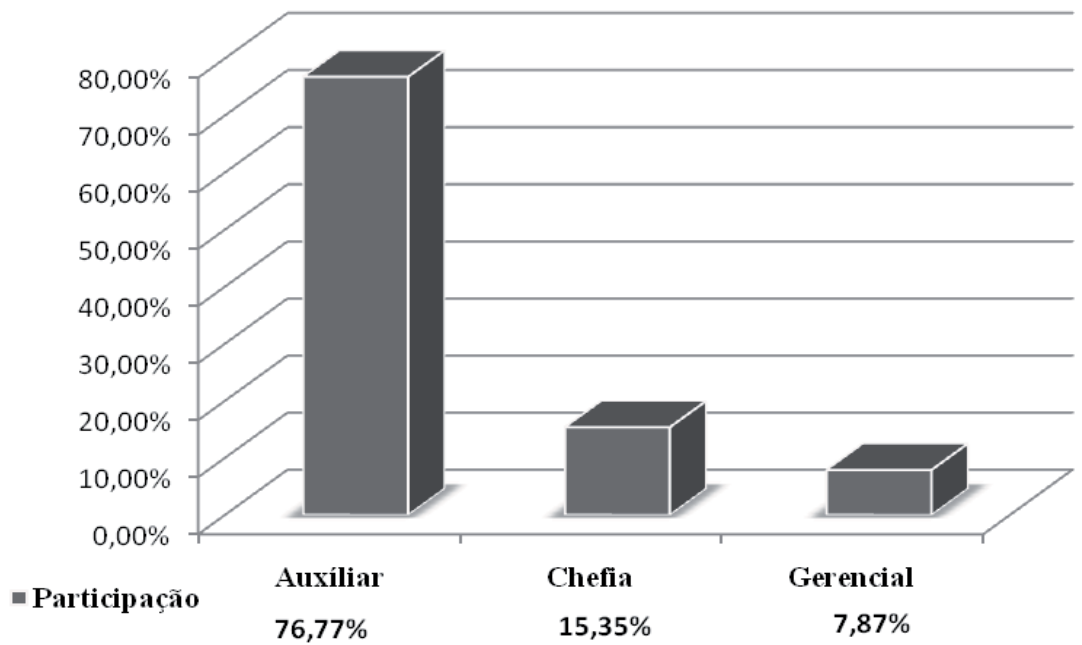

Fonte: Dados da pesquisa.

Esse fato é observado também por Guimarães (2006), e pode ser explicado devido à natureza dos cargos agrupados nesse nível, pois, como as atividades são de caráter operacional é normal que demandem uma quantidade maior de pessoas para desempenhá-las. E sendo assim a incidencia de rotatividade, em número absoluto tende a ser maior.

\subsubsection{Ofertas de Vagas de acordo com o Perfil do Empregador}

A seguir será apresentada a análise do perfil dos empregadores, verificando a representatividade de acordo com a origem, tamanho e segmento de atuação das empresas contratantes. As empresas que não forneceram essas informações estão classificadas como "outros", porém não influenciam a qualidade da análise.

a) Quanto à origem, pode-se observar que há predominância de ofertas de vagas por empresas nacionais. Sendo do total de vagas $87,01 \%$ destinadas a empresas nacionais e $11,81 \%$ para empresas multinacionais. 


\section{Gráfico 2 - Participação das vagas por origem da empresa}

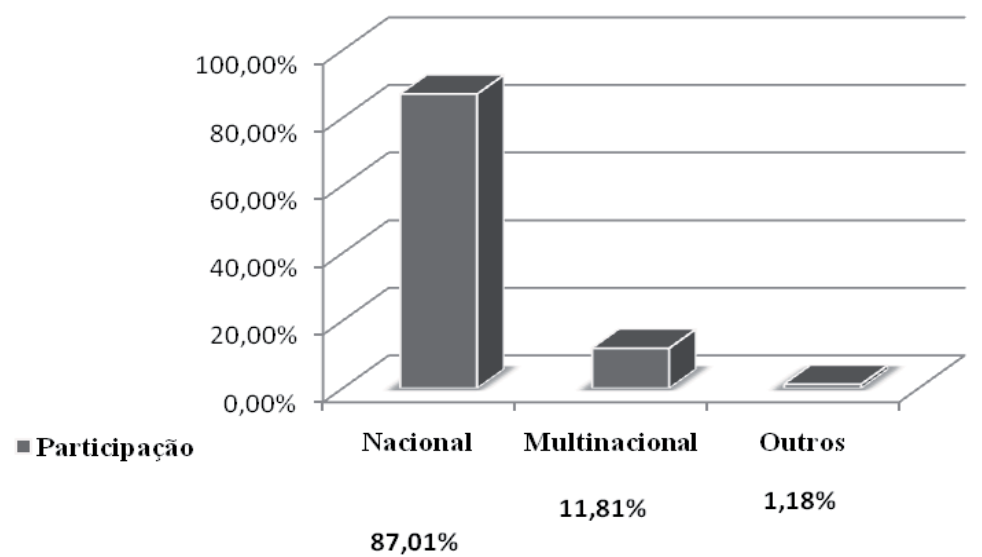

Fonte: Dados da pesquisa.

b) Já o gráfico 3, demonstra a proporção entre o tamanho das empresas contratantes se mantém entre as de pequeno e médio porte, sendo que as de grande porte representam $41,73 \%$ das vagas pesquisadas.

\section{Gráfico 3 - Participação das vagas por tamanho das empresas}

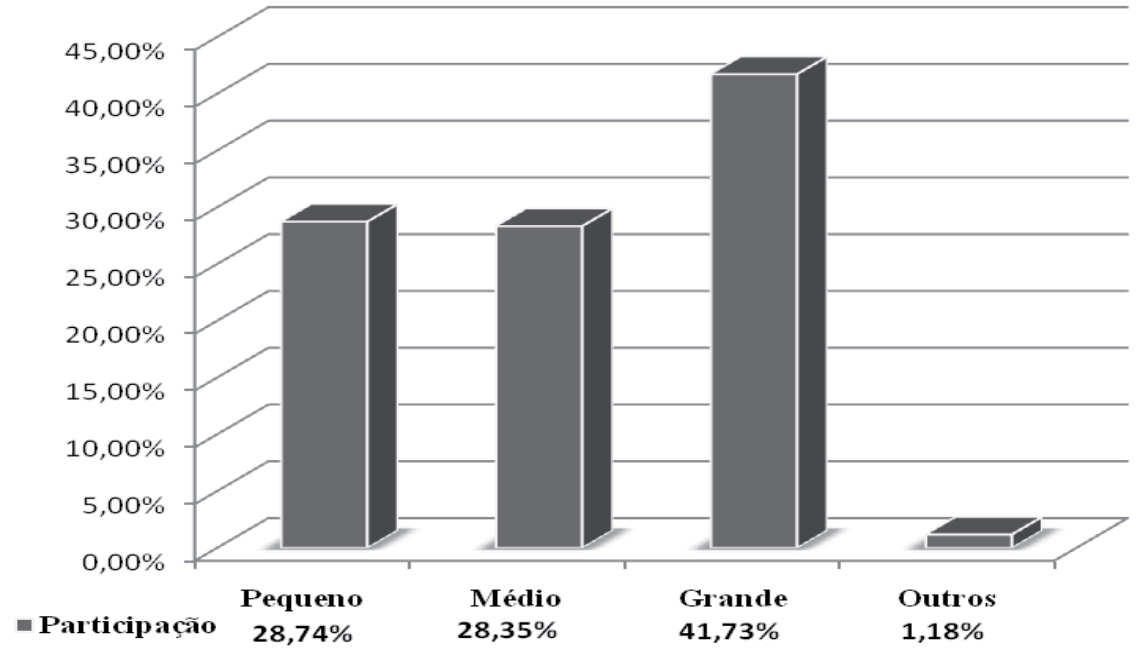

Fonte: Dados da pesquisa.

c) A participação das empresas segundo o ramo de atuação, está demonstrada conforme o gráfico 4 . 
Gráfico 4 - Participação das vagas por área de atuação das empresas

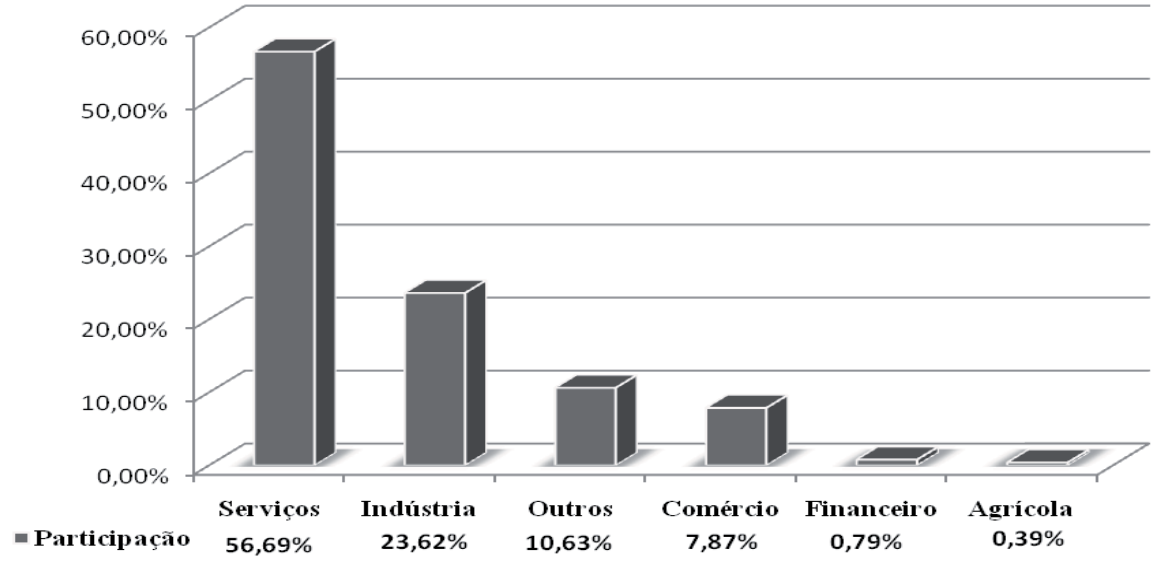

Fonte: Dados da pesquisa.

É possível observar que mais da metade das vagas são de empresas que atuam no setor de serviços, representando $56,69 \%$ do total da amostra, o segundo maior setor é o da Indústria com 23,62\%, seguido do setor de comércio com 7,87\% e de Finanças com 0,79 e agrícola com $0,39 \%$. Cerca de $10,63 \%$ não informou a ramo.

\subsection{Perfil do Ensino de Contabilidade nas IES}

A análise do currículo do curso de Ciências Contábeis das cinco IES possibilitou verificar qual a ênfase que cada entidade confere a formação do contador. As categorias com maior representatividade na grade curricular do curso de ciências contábeis foram referentes à contabilidade geral (introdutória, intermediária, avançada e tributária) e as classificadas como conhecimentos diversos (atividades complementares, Projeto de Conclusão de Curso, Perícia e Arbitragem).

$\mathrm{Na}$ Universidade positivo pode-se identificar ênfase maior nas áreas do conhecimento relacionadas à Contabilidade e Legislação societária e tributária, em segundo lugar as áreas de formação em conhecimentos gerais, e para as áreas de administração, economia e finanças. A Pontíficia Universidade Católica do Paraná diferencia-se da UP por dar maior ênfase a área de contabilidade e gestão empresarial ao invés dos conhecimentos classificados com gerais.

A FAE dá maior enfase a área de conhecimentos gerais, contabilidade e legislação societária e tributária seguido por administração, economia e finanças. A Universidade Tuiuti do Paraná, diferencia-se das demais IES por dar maior ênfase primeiramente a contabilidade e legislação societária e tributária, em seguida aos conhecimentos gerais e em terceiro a contabilidade e gestão empresarial. 
4.3 Comparativo entre a Formação oferecida pelas IES e as Exigências de Conhecimento do Mercado

Após a análise dos conhecimentos exigidos pelo mercado, para atuar na profissão contábil, e os conhecimentos ofertados pelas IES, neste tópico objetivase responder a questão central do trabalho, onde será verificado se a formação oferecida pelas IES está alinhada a demanda do mercado de trabalho.

\subsubsection{Formação Oferecida pelas IES}

Embora o currículo contábil sofra algumas alterações de Instituição para Instituição, optou-se por realizar uma média, a fim de obter uma análise geral do curso de Ciências Contábeis. Mediante a análise da Tabela 1, pode-se chegar à análise "geral" do currículo para o curso de Ciências Contábeis.

Tabela 1 - Média da participação das categorias nas Grades Curriculares das IES

\begin{tabular}{|c|c|c|c|c|c|}
\hline DESCRIÇÃO DAS CATEGORIAS & UP & PUC PR & FAE & UTP & MÉDIA \\
\hline Categoria 1: Contabilidade e legislação societária e tributária & $24 \%$ & $35 \%$ & $24 \%$ & $30 \%$ & $28 \%$ \\
\hline Categoria 2: Contabilidade e gestão empresarial & $16 \%$ & $24 \%$ & $16 \%$ & $19 \%$ & $19 \%$ \\
\hline Categoria 5: Administração, Economia e Finanças. & $21 \%$ & $15 \%$ & $19 \%$ & $16 \%$ & $18 \%$ \\
\hline $\begin{array}{l}\text { Categoria 9: Conhecimentos diversos (projeto de conclusão de } \\
\text { curso, atividades complementares, etc...) }\end{array}$ & $22 \%$ & $5 \%$ & $22 \%$ & $17 \%$ & $17 \%$ \\
\hline $\begin{array}{l}\text { Categoria 8: Habilidades e atitudes ( ética, filosofia, comunicação } \\
\text { e expressão.) }\end{array}$ & $7 \%$ & $10 \%$ & $7 \%$ & $6 \%$ & $7 \%$ \\
\hline Categoria 4: Tecnologia da informação & $5 \%$ & $7 \%$ & $5 \%$ & $0 \%$ & $4 \%$ \\
\hline Categoria 6: Auditoria & $3 \%$ & $5 \%$ & $2 \%$ & $5 \%$ & $4 \%$ \\
\hline Categoria 3: Contabilidade Internacional & $3 \%$ & $0 \%$ & $2 \%$ & $2 \%$ & $2 \%$ \\
\hline Categoria 10: Experiência profissional & $0 \%$ & $0 \%$ & $2 \%$ & $5 \%$ & $2 \%$ \\
\hline Categoria 7: Idiomas estrangeiros & $0 \%$ & $0 \%$ & $0 \%$ & $0 \%$ & $0 \%$ \\
\hline
\end{tabular}

Fonte: Dados da pesquisa.

A as principais ênfases são dadas para os conhecimentos relacionados à: contabilidade societária, tributária e legislação; contabilidade gerencial, análise de custos, controladoria e gestão empresarial; conhecimentos gerais (atividades complementares, projeto de conclusão de curso, pericia, etc.); conhecimentos que envolvem Administração, Economia e Finanças; habilidades pessoais (Comunicação e Expressão , Ética, Sociologia, etc.); Tecnologia da Informação; Auditoria; Contabilidade Internacional, experiência profissional e idiomas estrangeiros.

\subsubsection{A Exigência do Mercado de Trabalho Para o Profissional Contábil}

Analisando os dados coletados nas ofertas de vagas de emprego, sem re- 
alizar a distinção entre níveis hierárquicos pode-se chegar a um aspecto "geral" das qualificações exigidas para o profissional contábil, conforme segue:

Gráfico 5 - Participação das categorias no total de vagas

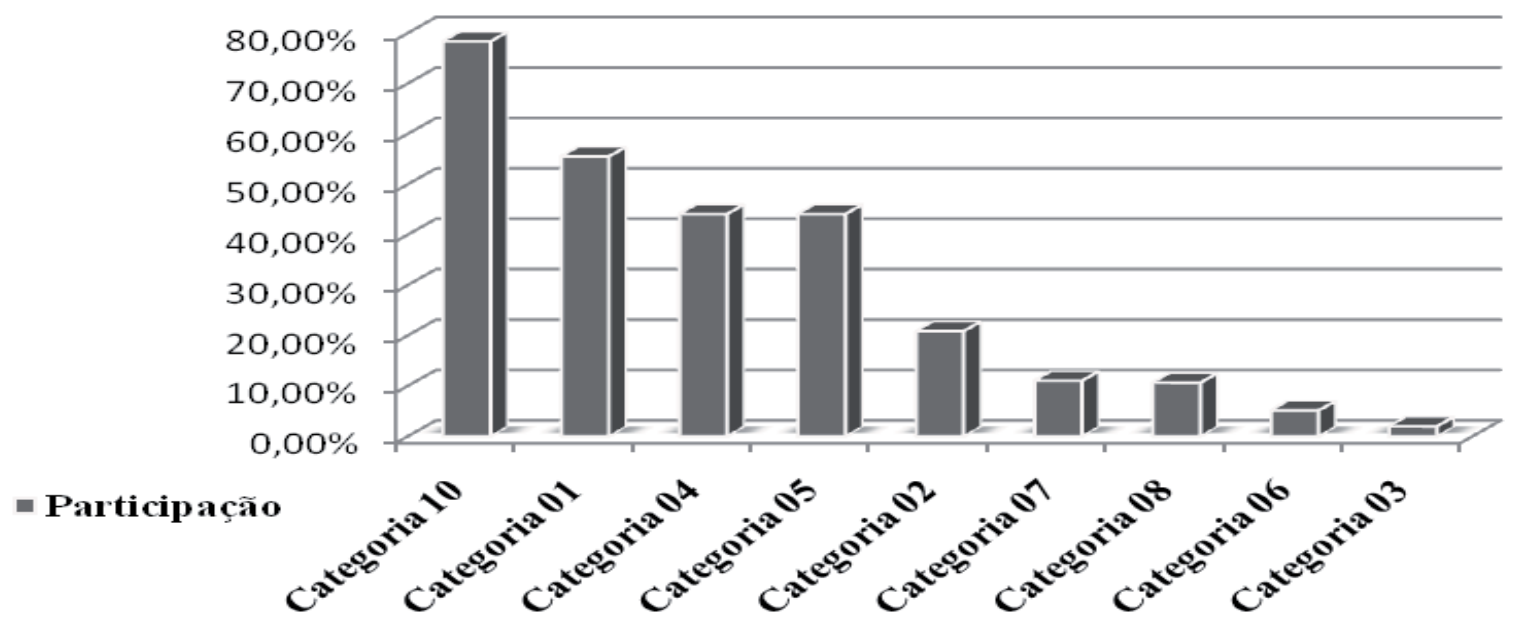

Fonte: Dados da pesquisa.

Em ordem de exigibilidade, as áreas de conhecimento são: experiência; conhecimentos em contabilidade e legislação societária e tributária; tecnologia da informação; conhecimentos em Administração, Economia e Finanças; Contabilidade Gerencial e Gestão empresarial, domínio de outros idiomas; habilidades e atitudes e Normas Internacionais de Contabilidade.

\subsubsection{Comparativo entre a Formação do Contador e as Exigências de Mercado}

Para comparar as duas análise foi necessário excluir a categoria 9, pois não foi contemplada na análise de ofertas de vagas devido a sua especificidade. A tabela a seguir demonstra o comparativo entre as exigências do mercado de trabalho e a ênfase de ensino das IES identificadas neste trabalho:

Analisando o Gráfico 5 é possível perceber que a matriz curricular das IES atende aos principais requisitos do mercado, porém não exatamente com a ênfase desejada. As categorias 10 (experiência profissional), 4 (tecnologia da informação), 2 (contabilidade e gestão empresarial) e 8 (habilidades e atitudes) apresentaram divergências quanto à exigibilidade. 
Tabela 2 - Participação geral das categorias por IES e Mercado de Trabalho

\begin{tabular}{|c|c|c|}
\hline Prioridade & Instituições de Ensino Superior & Mercado de Trabalho \\
\hline $1^{\mathrm{o}}$ & Categoria 1 & Categoria 10 \\
\hline $2^{\circ}$ & Categoria 2 & Categoria 1 \\
\hline $3^{\circ}$ & Categoria 5 & Categoria 4 \\
\hline $4^{\circ}$ & Categoria 8 & Categoria 5 \\
\hline $5^{\circ}$ & Categoria 4 & Categoria 2 \\
\hline $6^{\circ}$ & Categoria 6 & Categoria 7 \\
\hline $7^{\mathbf{o}}$ & Categoria 3 & Categoria 8 \\
\hline $8^{\circ}$ & Categoria 10 & Categoria 6 \\
\hline $9^{\circ}$ & Categoria 7 & Categoria 3 \\
\hline
\end{tabular}

Fonte: Dados da pesquisa.

As diferenças observadas podem ser explicadas devido ao foco das IES estar voltado a formação de profissionais com perfis gerenciais, ou então como salienta Coelho (2000 apud GUIMARÃES, 2006, p.121)

[...] vale observar que a universidade tem por objetivo formar o profissional da área, de acordo com as teorias da Ciência Contábil, estimular o espírito crítico, incentivar o trabalho de pesquisa, suscitar o desejo de aperfeiçoamento cultural e promover a divulgação dos conhecimentos.

Assim, pode-se se entender as diferenças de ênfase observadas no ensino em Ciências Contábeis, pois, o mesmo não se restringe a preparar seus alunos para a inserção no mercado de mercado, uma vez que também é de sua competência promover condições para o crescimento intelectual e pessoal dos discentes, e é claro o aprofundamento na ciência contábil propriamente dita.

\section{Considerações Finais}

\subsection{Conclusões}

Em relação à questão de pesquisa inicialmente formulada "As IES estão formando profissionais com as competências exigidas pelo mercado de trabalho?" verificou-se que "A formação de profissionais contábeis, oferecida pelas IES, está alinhada com as necessidades do mercado, pois as IES buscam acompanhar as exigências do mercado." foi confirmada, pois há alinhamento entre a matriz curricular e o mercado de trabalho do contador moderno. 
Em relação ao objetivo geral, a pesquisa concluiu que a formação dos profissionais contábeis oferecida pelas IES, condiz com as necessidades do mercado, embora existam algumas diferenças de ênfases nas áreas de conhecimento classificadas no estudo.

Verificou-se que a principal exigência para o profissional contábil é a experiência profissional, independente dos níveis hierárquicos, e crescente conforme a relevância do cargo. Essa necessidade do mercado não pode ser completamente "fornecida" pelas IES, uma vez que o profissional a adquire ao longo de sua carreira.

A segunda maior exigência identificada na pesquisa foram os conhecimentos em Contabilidade e Legislação Societária e Tributária para os níveis auxiliares e de chefia, enquanto que para o nível gerencial a segunda exigência foram conhecimentos em Administração, Economia e Finanças.

A baixa exigência em conhecimentos de Contabilidade Internacional pode ter sido influenciada pela pouca participação de empresas multinacionais na coleta de ofertas de emprego, o que pode também ter gerado impacto na exigência em conhecimento de idiomas estrangeiros. Outra hipótese para esse fato pode ser a pouca aplicabilidade em empresas de pequeno e médio porte, além da contabilidade internacional ser um assunto relativamente recente.

\subsection{Recomendações}

O presente trabalho procurou contribuir com os profissionais e estudantes de contabilidade no sentido de identificar as principais exigências que o mercado requer, para que assim possam se preparar para desempenhar sua profissão com sucesso.

E também contribuir com as IES que ofertam o curso de Ciências Contábeis, a fim de verificar se sua matriz curricular está condizente com a atual dinâmica do mercado, e se há necessidade de atualização.

Novos estudos poderão abordar o tema estudado nesse trabalho. Deste modo, recomenda-se realizar:

a) Um estudo que contemple um maior número de vagas de emprego, podendo assim verificar o perfil do profissional com maior precisão;

b) Estudo semelhante a este trabalho voltado para alguma área especifica de contabilidade, como por exemplo: Auditoria;

c) A análise entre perfil de formação proposto pelas IES e o perfil dos alunos formados por essas instituições.

\section{Referências}

BEUREN, Maria Ilsen; et al. Como elaborar trabalhos monográficos em conta- 
bilidade: teoria e prática, São Paulo: Atlas, 2003.

FARIA, Ana Cristina; QUEIROZ, Mario Roberto Braga de. Demanda de profissionais habilitados em contabilidade internacional no mercado de trabalho da cidade de São Paulo. Revista Universo Contábil, v.5, nº1, p.55-81, Jan./Mar., 2009.

GUIMARÃES, Paulo Cézar. Identificação do perfil profissiográfico do profissional de contabilidade requerido pelas empresas através de ofertas de emprego na região metropolitana de São Paulo. 2006. 148 f. Dissertação (Mestrado em Ciências Contábeis), Fundação Escola de Comércio Álvares Penteado - FECAP, São Paulo, 2006.

IUDÍCIBUS, Sérgio de. Contabilidade gerencial. 5. ed. São Paulo: Atlas, 1995.

LAFFIN, Marcos. De contador a professor: A trajetória da docência no ensino superior de contabilidade. Florianópolis (s.n), 2005.

LEAL, Edvalda Araújo; SOARES, Mara Alves; SOUSA, Edileusa Godói de. Perspectivas dos formandos do Curso de Ciências Contábeis e as Exigências do Mercado de Trabalho. Revista Contemporânea de Contabilidade, v.1, ${ }^{\circ} 10$, p. 147-159, Jul./Dez., 2008.

MACHADO, Vinicius Sucupira de Alencar; NOVA, Silvia Pereira de Castro Casa. Análise comparativa entre os conhecimentos desenvolvidos no curso de graduação em contabilidade e o perfil do contador exigido pelo mercado de trabalho: Uma pesquisa de campo sobre educação contábil. Revista de Educação e Pesquisa em Contabilidade, v.2, $\mathrm{n}^{\circ} 1$, p.1-23, Jan./Abr., 2008.

PELEIAS, Ivam Ricardo; SILVA, Glauco Peres da; SEGRETI, João Bosco; CHIROTTO, Amanda Russo. Evolução do Ensino da contabilidade no Brasil: Uma análise histórica. Revista Contabilidade e Finanças, Edição 30 anos de doutorado, p.19-32, Junho, 2007.

PIRES, Charline Barbosa; OTT, Ernani; DAMACENA, Claudio. "Guarda-Livros" ou "Parceiro de Negócios"? Uma análise do perfil profissional requerido pelo mercado de trabalho para contadores na região metropolitana de Porto Alegre (RMPA). Revista Contabilidade Vista \& Revista, v.20, n³. P.157-187, jul./set., 2009.

SCHMIDT, Paulo. História do Pensamento Contábil. Porto Alegre: Bookman, 2000. 